\title{
Permanent congenital hypothyroidism
}

INSERM

\section{Source}

INSERM. (1999). Orphanet: an online rare disease and orphan drug data base. Permanent congenital hypothyroidism. ORPHA:226292

Permanent congenital hypothyroidism is a type of congenital hypothyroidism ( $\mathrm{CH}$; see this term), a thyroid hormone deficiency present from birth. 